Molecular biology and genetics / Biologie et génétique moléculaires

\title{
Prospectives for applying molecular and genetic methodology to improve wheat cultivars in drought environments
}

\author{
Zhao Chang-Xing a,b,*, Guo Ling-Yu ${ }^{\text {a }}$, Cheruth Abdul Jaleel ${ }^{\mathrm{c}}$, Shao Hong-Bo ${ }^{\text {de, }, \text {, }, *}$, \\ Yang Hong-Bing ${ }^{g}$ \\ a College of Plant Science and Technology, Qingdao Agricultural University, Qingdao 266109, China \\ ${ }^{\mathrm{b}}$ State Key Laboratory of Urban and Regional Ecology Research Center for National Status, Research Center for Eco-Environmental Sciences, \\ The Chinese Academy of Sciences, Beijing 100085, China \\ c Stress Physiology Laboratory, Department of Botany, Annamalai University, Annamalainagar 608002, Tamil Nadu, India \\ $\mathrm{d}$ Binzhou University, Binzhou 256603, China \\ e State Key Laboratory of Soil Erosion and Dryland Farming on the Loess Plateau, Institute of Soil and Water Conservation, \\ Chinese Academy of Science, Yangling 712100, China \\ ${ }^{\mathrm{f}}$ Institute of Life Sciences, Qingdao University of Science \& Technology, Zhengzhou Road 53, Qingdao 266042, China \\ $\mathrm{g}$ College of Life Sciences, Qingdao Agricultural University, Qingdao 266109, China
}

Received 3 May 2008; accepted after revision 27 May 2008

Presented by Philippe Morat

\begin{abstract}
With the advent of molecular biotechnologies, new opportunities are available for plant physiologists to study the relationships between wheat traits and their genetic control. The functional determinations of all genes that participate in drought adaptation or tolerance reactions are expected to provide an integrated understanding of the biochemical and physiological basis of stress responses in wheat. However, despite all the recent technological breakthroughs, the overall contribution of genomics-assisted breeding to the release of drought-resilient wheat cultivars has so far been marginal. This paper critically analyses how biotechnological, genetic and information tools can contribute to accelerating the release of improved, drought-tolerant wheat cultivars. Armed with such information from established models, it will be possible to elucidate the physiological basis of drought tolerance and to select genotypes with an improved yield under water-limited conditions. To cite this article: $\boldsymbol{C}$.-X. Zhao et al., C. R. Biologies 331 (2008).
\end{abstract}

(C) 2008 Académie des sciences. Published by Elsevier Masson SAS. All rights reserved.

Keywords: Wheat (Triticum aestivum L.); Drought environments; Comparative mapping; Segregating population; Genetic linkage maps;

Genomics-assisted breeding

\section{Introduction}

\footnotetext{
* Corresponding authors.

E-mail addresses: zhaochangxing@126.com (C.-X. Zhao), shaohongbochu@126.com (H.-B. Shao).
}

Wheat (Triticum aestivum L.) production is adversely affected by drought in 50\% of the area under production in the developing and $70 \%$ in the devel- 
oped countries [1]. As water resources are likely to decline in the coming decades [2], the areas devoted to wheat production will be increasingly threatened by water availability. Hence, improving wheat adaptation to drought will acquire a greater socioeconomic importance across the globe than it currently has.

As shortage of water is more limiting to crop production in arid regions than any other single factor, a better understanding and control of the mechanisms that enable a plant to adapt to low water potentials and maintain the processes involved in growth, development and production, has been an aim of breeding for drought resistance [3]. Therefore, the analysis of the physiological responses of various wheat genotypes to water stress was liable to lead to the development of more efficient selection criteria $[4,5]$.

Whichever adaptation strategy is exerted in the wheat plant as a response to drought, it is paramount to elucidate the central element of control from the atomistic, reductionistic view. The dissection can be conducted at the translational, transcriptional or genetic levels for furthering the manipulation of the components of a genotypic response [6,7]. During the past three decades, 76 genetic and information tools have been developed (and adopted) to reveal basic features in the genetics and expression of different wheat species (Fig. 1). Some are presented as following.

\section{Comparative mapping}

Comparative maps allow transfer of information about genetic control of traits from species with small diploid genomes, such as rice (Oryza sativa L.), to species with more complex genomic structures (increased repetitive DNA, polyploidy) and less economic support $[8,9]$. Because of the size and complexity of the genomes, it may not be appropriate to sequence the entire genomes of wheat (Triticum ssp.), rye (Secale cereale L.), oat (Avena sativa L.), or barley (Hordeum vulgare L.) $[9,10]$. However, alternative strategies involving identification of gene-rich regions of the Triticeae genome and comparison of the genome structure and genetic colinearity with rice, maize (Zea mays L.), sorghum (Sorghum vulgare L.), and other species provide Triticeae researchers with the knowledge and tools necessary for genetic parity with simpler genomes.

Crop species of the Poaceae display a remarkable level of genetic similarity despite their evolutionary divergence 65 million years ago [11]. Molecular markers have been used to develop comparative chromosome maps for several members of the Gramineae and these have been used to study genes of agronomic importance across species $[12,13]$. Large segments of the genomes of maize, sorghum, rice, wheat, and barley conserve gene content and order [14-17], although the correspondence has been modified by duplications, inversions, and translocations. For the domesticated grasses, the conserved linkage blocks and their relationships with rice linkage groups provides the insight into the basic organization of the ancestral grass genome [18]. This allows the transfer of information from species with small diploid genomes, such as rice, to species with more complex genomic structures, such as that of wheat $[16,19]$.

Despite the progress in comparative mapping, the application of this technology, especially for wheat, rye, oat, and barley will not be realized unless scientifically sound strategies for studying drought tolerance are devised that allow researchers to utilize genetic tools and information developed for model species [20]. This will require more detailed comparative genetic analysis from the DNA sequence of genes all the way to comparative analysis of QTL (quantitative trait locus).

\section{Bulked segregant analysis}

The usual method to locate and compare loci regulating quantitative traits (QTLs) requires a segregating population of plants with each one genotyped with molecular markers [21]. However, plants from such segregating populations can also be grouped according to phenotypic expression of a trait and tested for differences in allele frequency between the population bulks: bulk segregant analysis (BSA) [21,22]. The same probes used for making a genetic map (e.g., isozyme, RFLP, RAPD, etc.) can be used for BSA [23]. A molecular marker showing polymorphism between the parents of the population and which is closely linked to a major QTL regulating a particular trait will mainly cosegregate with that QTL, i.e. segregate according to the phenotype if the QTL has a large effect [21-24]. Thus, if plants are grouped according to the expression of the trait and extreme groups tested with that polymorphic marker, the frequency of the two marker alleles present within each of the two bulks should deviate significantly from the ratio of 1:1 expected for most populations [23]. As chromosomal locations of many molecular markers have now been determined in many species, the map location of closely-linked QTLs can therefore be deduced without having to genotype every individual in segregating populations [25].

This has been used successfully with composite populations of wheat to locate QTLs associated with yield under severe drought. An inbred line derived from one 


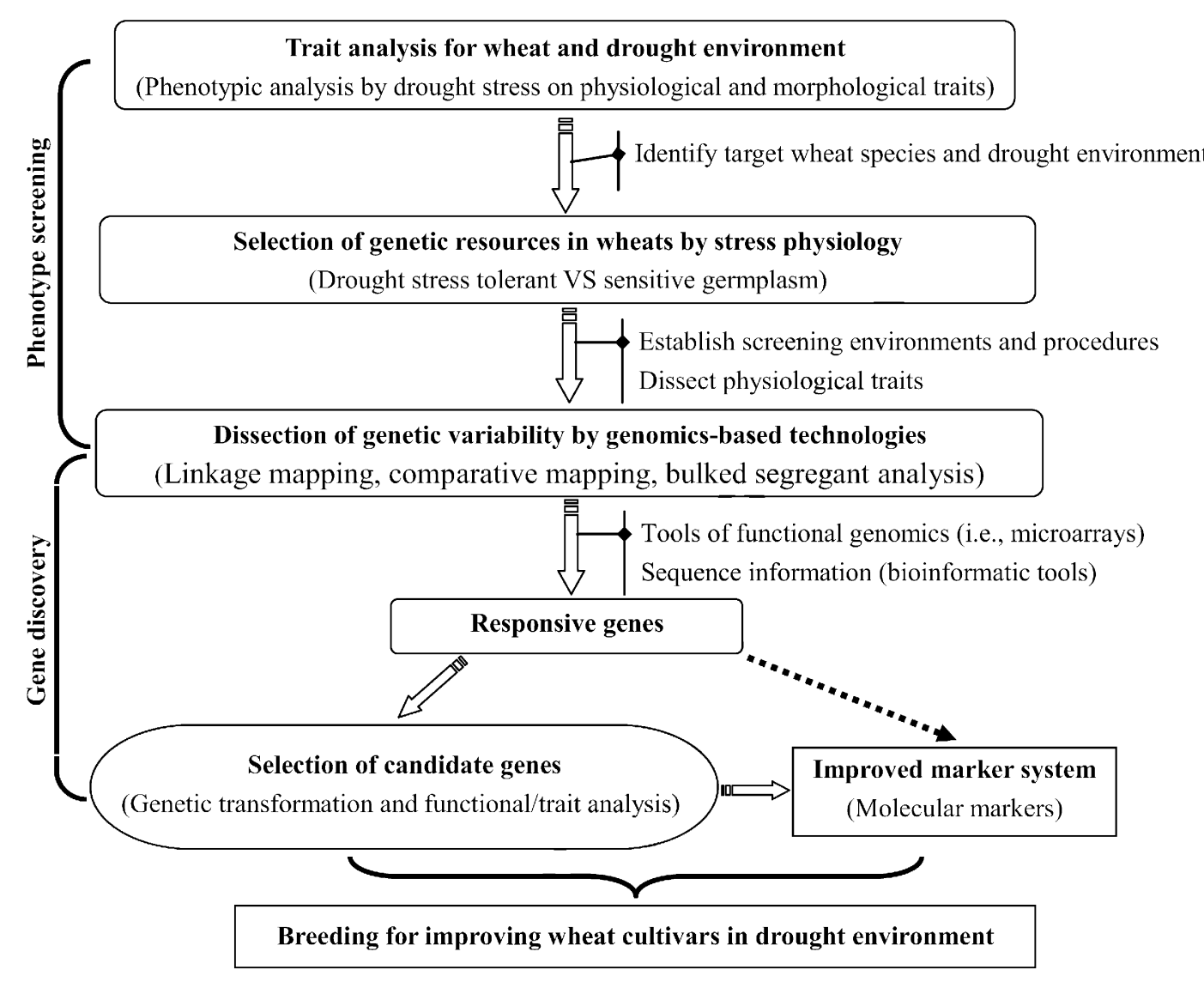

Fig. 1. Molecular strategy for increasing drought tolerance uses a top-down approach (phenotype to gene) by beginning with trait analyses in drought environment.

of the populations selected for higher drought yield has been crossed with a drought-susceptible inbred line to produce a mapping population for QTL analysis of physiological and developmental traits likely to regulate yield under drought $[21,26]$. Some researchers used bulked segregant analysis (BSA) to identify microsatellite makers associated with water-stress tolerance in wheat, and found that one microsatellite fragment that was present in tolerant parent wheat and the tolerant bulk but absent in the sensitive parent wheat and sensitive bulk [27]. Future work to identify traits having QTLs with flanking markers showing significant allele frequency differences in the BSA studies will indicate that those traits are likely to be important in determining yield under drought.

\section{Linkage mapping}

The establishment of genetic linkage maps provides the basis for mapping the gene(s) responsible for the expression of traits of interest. In wheat, such maps have also corroborated cytological evidence of major chro- mosome rearrangements [28-30] and have allowed the comparative mapping among related species [14,31,32].

Within the span of the past thirty years, molecular markers have been considered important biotechnology tools for enhancing the magnitude of plant breeding. From the conceptualization and delineation of perspectives in their use in breeding programmes [33] to their usefulness and efficacy proposals [34,35], the methodologies have ample applications: characterization of genetic diversity [36,37], introgression of exogenous genetic material for diversity increment [33], advancement in novel varieties release [38] diagnostics [39] or selection tools [40].

In several cereal species, genetic linkage maps have allowed the identification of regions controlling some traits related to the response to drought. Different segregating populations from maize, rice, sorghum, barley, durum (tetraploid) wheat and sugar cane (amongst others) have been studied for many different criteria or quantitative characters, such as phenology, plant architecture, metabolic pathways, water-use efficiency or carbon isotope discrimination [41-44]. In contrast, de- 
velopments in molecular genetics in wheat have been relatively slow and exiguous. Explanations are ample: wheat's ploidy level $(2 n=6 x=42$, AABBDD); genome size (estimated to contain 18.1 picograms of DNA per haploid nucleus [45], equivalent to ca. $16 \times$ $10^{6}$ kilobase pairs); and genomic complexity ( $>75 \%$ consists of repeated DNA sequences of varying degrees of reiteration and length, with a lesser proportion (ca. $20 \%$ ) of low-copy number or unique sequences [46]).

The wheat hexaploid nature and its amenity to cytogenetic manipulation do offer unique tools to geneticists, allowing them to determine evidence of major chromosome rearrangements [28,29] and the comparison of linkage maps among related species $[14,47]$. The low number of quantitative traits dissected into their QTL is a reflection of the focus given to simply inherited traits $[48,49]$ and the difficulty of building comprehensive genetic linkage maps for wheat [50-52].

\section{Gene discovery}

Rapid discovery of genes by large-scale partial sequencing of selected cDNA clones or expressed sequence tags (ESTs) is the initial step towards characterization and categorization of genetically complex abiotic stress responses [53-55]. Expressed sequence tag (EST) analysis was proposed for efficient sampling of a genome for information about genes that could be useful in searching at databases [56]. By searching online databases for similar genes with known function, one can determine if a specific gene (or gene motif) has been found in the same or other organisms and if its function has been determined. These ESTs can also be useful for further laboratory work in gene expression, mapping and direct alteration of the organism [57-59]. EST information can be merged with that of a protein database to provide information on patterns of gene expression. For the long term, EST information will be a critical resource for crop improvement and will be used extensively for locating genes, understanding changing patterns of gene expression, and biotechnological modification of traits. However, identifying and mapping all the expressed genes in a species without sequencing the entire genome is a complex task.

Extensive EST collections and databases already exist for Arabidopsis [60] and rice [61,62], while large-scale EST sequencing initiatives for various crop species is under course $[63,64]$, including that of wheat. However, such collections are biased towards highto-moderate abundance studies that are derived from different tissues, organs or cells, different developmental stages, various external stimuli, and treatments with plant-growth regulators [65]. In contrast, relatively few studies have focused specifically on ESTs from plants that have been exposed to environmental stresses [65, 66].

\section{Candidate genes}

A candidate gene is such that is associated with the variation in a trait, involved with the development or physiology of the trait. Frequently, candidate genes are sequenced genes of known or suspected function and may belong to biochemical or regulatory pathways $[67$, 68]. Identifying the genes involved in complex trait governance derived from QTL analysis can provide different kinds of genetic information, regularly over a broader range of germplasm. Because there may be large numbers of genes located in the region of a QTL, the odds of identifying the gene that actually controls the expression of the trait appear to be quite low; however, a number of factors can increase the odds of success, especially as the number of genes sequenced increases [69]. Translational genomics of these candidate genes using model plants provided encouraging results, but the field testing of transgenic crop plants for better performance and yield is still minimal [70]. Expression microarrays provide new insights into physiological and biochemical pathways of drought tolerance, and thus can lead to identification of novel candidate genes that can rapidly advance breeding for drought tolerance [71, 72].

Geneticists are using association genetics to dissect complex adaptive traits and discover the underlying genes. In parallel, they are using resequencing of candidate genes and modern population genetics methods to discover genes under natural selection. This combined approach is identifying the most important genes that determine patterns of complex trait adaptation observed in many crop populations [73]. In addition, researchers are now routinely using candidate gene-based mapping and genome-wide linkage disequilibrium and association analysis in addition to classical QTL mapping to identify markers broadly applicable to breeding programs.

\section{Functional genomics}

Using DNA chips [74], it may be possible to determine the relative importance (contribution) of each gene to some of the studied physiological traits involved in drought adaptation at different phenological stages under different water regimes $[13,20,75,76]$. Some potential uses include the ability to search for clones di- 
Table 1

Some examples of transgenic wheats reporting effects under drought environment

\begin{tabular}{lll}
\hline Target & Gene & Effect \\
\hline Mannitol & $m t l D$ & $\begin{array}{l}\text { In pot experiment after 30 days, drought transgenic line had } \\
\text { greater dry weight, plant height and tiller number than control } \\
\text { plants } \\
\text { After water was withheld for 10 days, there was less wilting in } \\
\text { transgenic lines than control } \\
\text { DREB }\end{array}$ \\
LEA proteins & HVA1 & $\begin{array}{l}\text { Higher root and shoot biomass than controls under drought } \\
\text { stress and improved recovery after drought }\end{array}$ \\
Lipid transfer protein & TaLTP1 & $\begin{array}{l}\text { Increasing by water stresses, such as by treatment at several } \\
\text { PEG concentrations and NaCl, by hormone treatments } \\
\text { Increasing in response to mild drought stress in the flag leaf }\end{array}$ \\
Membrane protein associated-protein & TaVAP &
\end{tabular}

rectly or indirectly that are related to major gene differences, mutations, QTLs and for genes showing changes in gene expression during a developmental time-course or in a tissue basis [74,77-80]. In grain crops, timecourse studies of seed development, gene expression during meiosis, and responses to specific environmental stimuli will identify expressed genes [13]. This will assign function to ESTs that will serve as potential candidates for mapped qualitative or quantitative loci affecting important traits. Characterization of the expression patterns of genes involved in genotype-by-environment interactions may eventually help unravel the complexities of the phenomena [77,81]. The success necessitates the application of genomics to the rapid validation of gene function and mode of action. As one example, the development of C-box binding factors (CBFs) for enhanced freezing and drought tolerance has been rapidly advanced because of the improved understanding generated by genomics technologies [68]. Harnessing the full potential of genomics-assisted wheat breeding will require a multidisciplinary approach and an integrated knowledge of the molecular and physiological processes influencing tolerance to drought.

\section{Conclusions}

Drought stress is one of the major limitations to wheat productivity. To develop crop plants with enhanced tolerance of drought stress, a basic understanding of physiological, biochemical and gene regulatory networks is essential. Various functional genomics tools have helped to advance our understanding of stress signal perception and transduction, and of the associated molecular regulatory network. These tools have revealed several stress-inducible genes and various transcription factors that regulate the drought-stressinducible systems (Table 1).

Meanwhile, new initiatives are being made in the area of plant biotechnology, especially in the area of functional genomic efforts by public and private sector research establishments. Genomes of cereal species with simpler genetic systems such as rice has been sequenced and maize sequence information will become available in the near future. Species with more complex genomes such as wheat can benefit by the information that will become available from the other species such as rice and maize by using candidate gene approaches. It is necessary to develop capacities to handle massive amounts of data that will become available from large-scale profiling experiments. For example, improving transformation efficiency as well as selection strategies for high throughput mutagenesis experiments will be two critical areas of research for the ultimate assignment of function to the numerous wheat genes that are being discovered using the new genomic tools.

In a word, the elucidation of genomic regions associated with the expression of traits involved in drought adaptation, the novel genes discovery or the determination of their expression patterns in response to drought stress will provide the basis of effective engineering strategies leading to enhanced wheat germplasm for specific agroecological niches. For any molecular assessment to be performed, it is paramount to firstly establish the plant adaptation strategy to overcome drought. Further, an account of stress-inducible regulatory genes that have been transferred into wheat plants to enhance stress tolerance is discussed as possible modes of integrating information gained from functional genomics into knowledge-based breeding programs.

\section{Acknowledgements}

Zhao Chang-Xing would like to acknowledge financial support from Doctoral Foundation of Qingdao Agricultural University (630523) and Project of Shandong Provincial Education Department (J06K57). 


\section{References}

[1] R.M. Trethowan, W.H. Pfeiffer, Challenges and future strategies in breeding wheat for adaptation to drought stressed environments: A CIMMYT wheat program perspective, in: J.-M. Ribaut, D. Poland (Eds.), Molecular approaches for the genetic improvement of cereals for stable production in water-limited environments, A strategic planning workshop held at CIMMYT El Batan, Mexico, 21-25 June 1999, CIMMYT, Mexico DF, 2000, pp. $45-48$.

[2] World Meteorological Organisation, Comprehensive Assessment of the Freshwater, Resources of the World, Geneva, Switzerland, 1997.

[3] M.M. Chaves, M.M. Oliveira, Mechanisms underlying plant resilience to water deficits: Prospects for water-saving agriculture, J. Exp. Bot. 55 (2004) 2365-2384.

[4] M. Vazifedoust, J.-C. van Dam, R.A. Feddes, M. Feizi, Increasing water productivity of irrigated crops under limited water supply at field scale, Agric. Water Manage. 95 (2008) 89-102.

[5] M.J. Foulkes, R. Sylvester-Bradley, R. Weightman, J.W. Snape, Identifying physiological traits associated with improved drought resistance in winter wheat, Field Crops Res. 103 (2007) $11-24$.

[6] M. van Ginkel, F. Ogbonnaya, Novel genetic diversity from synthetic wheats in breeding cultivars for changing production conditions, Field Crops Res. 104 (2007) 86-94.

[7] A.K. Sahrawat, D. Becker, S. Lütticke, H. Lörz, Genetic improvement of wheat via alien gene transfer, an assessment, Plant Sci. 165 (2003) 1147-1168.

[8] T. Izawa, Y. Takahashi, M. Yano, Comparative biology comes into bloom: Genomic and genetic comparison of flowering pathways in rice and Arabidopsis, Curr. Opin. Plant Biol. 6 (2003) 113-120.

[9] M. Dilbirligi, M. Erayman, B.T. Campbell, H.S. Randhawa, P.S. Baenziger, I. Dweikat, K.S. Gill, High-density mapping and comparative analysis of agronomically important traits on wheat chromosome 3A, Genomics 88 (2006) 74-87.

[10] R.K. Varshney, R. Sigmund, A. Börner, V. Korzun, N. Stein, M.E. Sorrells, P. Langridge, A. Graner, Interspecific transferability and comparative mapping of barley EST-SSR markers in wheat, rye and rice, Plant Sci. 168 (2005) 195-202.

[11] A.H. Paterson, Y.R. Lin, S. Li, K.F. Schertz, J.F. Doebley, S.R.M. Pinson, S.C. Liu, J.W. Stansel, J.E. Irvine, Convergent domestication of cereal crops by independent mutations at corresponding genetic loci, Science 269 (1995) 1714-1717.

[12] R.K.M. Hay, R.P. Ellis, The control of flowering in wheat and barley: what recent advances in molecular genetics can reveal, Ann. Bot. 82 (1998) 541-554.

[13] R. Tuberosa, S. Salvi, Genomics-based approaches to improve drought tolerance of crops, Trends Plant Sci. 11 (2006) 405-412.

[14] S. Ahn, J.E. Anderson, M.E. Sorrells, S.D. Tanksley, Homoeologous relationships of rice, wheat and maize chromosomes, Mol. Gen. Genet. 241 (1993) 483-490.

[15] S. Ahn, S.D. Tanksley, Comparative linkage maps of the rice and maize genomes, Proc. Natl Acad. Sci. USA 90 (1993) 7980 7984.

[16] M.D. Gale, K.M. Devos, Comparative genetics in the grasses, Proc. Natl Acad. Sci. USA 95 (1998) 1971-1974.

[17] S.H. Hulbert, T.E. Richter, J.D. Axtell, J.L. Bennetzen, Genetic mapping and characterization of sorghum and related crops by means of maize DNA probes, Proc. Natl Acad. Sci. USA 87 (1990) 4251-4255.
[18] G. Moore, K.M. Devos, Z. Wang, M.D. Gale, Cereal genome evolution - grasses, line up and form a circle, Curr. Biol. 5 (1995) 737-739.

[19] S. McCouch, Toward a plant genomics initiative: Thoughts on the value of cross-species, and cross-genera comparisons in the grasses, Proc. Natl Acad. Sci. USA 95 (1998) 1983-1985.

[20] L. Cattivelli, F. Rizza, F.W. Badeck, E. Mazzucotelli, A.M. Mastrangelo, E. Francia, C. Marè, A. Tondelli, A.M. Stanca, Drought tolerance improvement in crop plants: An integrated view from breeding to genomics, Field Crops Res. 105 (2008) 1-14.

[21] S. Quarrie, V. Lazic-Jancic, D. Kovacevic, A. Steed, S. Pekic, Bulk segregant analysis with molecular markers and its use for improving drought resistance in maize, J. Exp. Bot. 50 (1999) 1299-1306.

[22] M.J. Brauer, C.M. Christianson, D.A. Pai, M.J. Dunham, Mapping novel traits by array-assisted bulk segregant analysis in Saccharomyces cerevisiae, Genetics 173 (2006) 1813-1816.

[23] I.J. Mackay, P.D.S. Caligari, Efficiencies of $F_{2}$ and backcross generations for bulked segregant analysis using dominant markers, Crop Sci. 40 (2000) 626-630.

[24] R.W. Michelmore, I. Paran, R.V. Kesseli, Identification of markers linked to disease-resistance genes by bulked segregant analysis: a rapid method to detect markers in specific genomic regions by using segregating populations, Proc. Natl Acad. Sci. USA 88 (1991) 9828-9832.

[25] R. Kölliker, E.S. Jones, M.Z.Z. Jahufer, J.W. Forster, Bulked AFLP analysis for the assessment of genetic diversity in white clover (Trifolium repens L.), Euphytica 121 (2001) 305-315.

[26] R. Tuberosa, S. Salvi, M.C. Sanguineti, P. Landi, M. Maccaferri, S. Conti, Mapping QTLs regulating morpho-physiological traits and yield: Case studies, shortcomings and perspectives in drought-stressed maize, Ann. Bot. 89 (2002) 941-963.

[27] A. Ahu, G. Nermin, Search for microsatellite markers associated with water-stress tolerance in wheat through bulked segregant analysis, Mol. Biotech. 23 (2003) 97-106.

[28] K.M. Devos, J. Dubcovsky, J. Dvorák, C.N. Chinoy, M.D. Gale, Structural evolution of wheat chromosomes 4A, 5A and 7B and its impact on recombination, Theor. Appl. Genet. 91 (1995) 282288.

[29] J.C. Nelson, M.E. Sorrells, A.E. Van Deynze, Y.H. Lu, M. Atkinson, M. Bernard, P. Leroy, J.D. Faris, J.A. Anderson, Molecular mapping of wheat: Major genes and rearrangements in homoeologous groups 4, 5 and 7, Genetics 141 (1995) 721-731.

[30] J. Dubcovsky, M.C. Luo, G.Y. Zhong, R. Bransteitter, A. Desai, A. Kilian, A. Kleinhofs, J. Dvorak, Genetic map of diploid wheat, Triticum monococcum L., and its comparison with maps of Hordeum vulgare L., Genetics 143 (1996) 983-999.

[31] S. Chao, W.J. Zhang, J. Dubcovsky, M. Sorrells, Evaluation of genetic diversity and genome-wide linkage disequilibrium among U.S. wheat (Triticum aestivum L.) germplasm representing different market classes, Crop Sci. 47 (2007) 1018-1030.

[32] C.P. Joshi, H.T. Nguyen, RAPD (random amplified polymorphic DNA) analysis based intervarietal genetic relationships among hexaploid wheats, Plant Sci. 93 (1993) 95-103.

[33] S.D. Tanskley, N.D. Young, A.H. Paterson, M.W. Bonierbale, RFLP mapping in plant breeding: New tools for an old science, Bio/Technology 7 (1989) 257-264.

[34] M. Lee, DNA markers and plant breeding programs, Adv. Agron. 55 (1995) 265-344.

[35] M. Sorrells, The application of comparative genetics to wheat improvement, in: M.M. Kohli, M. Francis (Eds.), Application of Biotechnologies to wheat breeding, Proceedings of a Conference 
at La Estanzuela, Uruguay, 19-20 November 1998, Montevideo, Uruguay, pp. 17-32.

[36] G. Caetano-Anollés, B.J. Bassam, P.M. Gresshoff, DNA amplification fingerprinting: A strategy for genome analysis, Plant Mol. Biol. Rep. 9 (1991) 294-307.

[37] S. Dreisigacker, P. Zhang, M.L. Warburton, B. Skovmand, D. Hoisington, A.E. Melchinger, Genetic diversity among and within CIMMYT wheat landrace accessions investigated with SSRs and implications for plant genetic resources management, Crop Sci. 45 (2005) 653-661.

[38] S. Eathington, Practical uses of molecular markers in a commercial breeding program (Monsanto), in: S. Higman (Ed.), Proc. International Plant Breeding Symposium - Honouring John Dudley, 20-25 August 2006.

[39] R. D'Ovidio, O.D. Anderson, PCR analysis to distinguish between alleles of a member of a multigene family correlated with wheat bread-making quality, Theor. Appl. Genet. 88 (1994) 759763.

[40] J.M. Ribaut, X. Hu, D. Hoisington, D. González-de-León, Use of STSs and SSRs as rapid and reliable preselection tools in a marker-assisted selection scheme, Plant Mol. Biol. Rep. 15 (1997) 154-162.

[41] H. Grausgruber, M. Oberforster, G. Ghambashidze, P. Ruckenbauer, Yield and agronomic traits of Khorasan wheat (Triticum turanicum Jakubz.), Field Crops Res. 91 (2005) 319-327.

[42] W.L. Rooney, Sorghum improvement-integrating traditional and new technology to produce improved genotypes, Adv. Agron. 83 (2004) 37-109.

[43] C.T. Hash, A.G. Bhasker Raj, S. Lindup, A. Sharma, C.R. Beniwal, R.T. Folkertsma, V. Mahalakshmi, E. Zerbini, M. Blümmel, Opportunities for marker-assisted selection (MAS) to improve the feed quality of crop residues in pearl millet and sorghum, Field Crops Res. 84 (2003) 79-88.

[44] S.P. Kiani, P. Talia, P. Maury, P. Grieu, R. Heinz, A. Perrault, V. Nishinakamasu, E. Hopp, L. Gentzbittel, N. Paniego, A. Sarrafi, Genetic analysis of plant water status and osmotic adjustment in recombinant inbred lines of sunflower under two water treatments, Plant Sci. 72 (2007) 773-787.

[45] M.D. Bennett, Nuclear DNA content and minimum generation time in herbaceous plants, Proc. R. Soc. Lond., Ser. B 181 (1972) 109-135.

[46] D.B. Smith, R.B. Flavell, Characterisation of the wheat genome by renaturation kinetics, Chromosoma 50 (1975) 223-242.

[47] K.M. Devos, S. Chao, Q.Y. Li, M.C. Simonetti, M.D. Gale, Relationship between chromosome 9 of maize and wheat homeologous group 7 chromosomes, Genetics 138 (1994) 1287-1292.

[48] C. Taylor, K.W. Sheperd, P. Langridge, A molecular genetic map of the long arm of chromosome $6 \mathrm{R}$ or rye incorporating the cereal cyst nematode resistance gene, Cre R, Theor. Appl. Genet. 97 (1998) 1000-1012.

[49] D.J. Somers, G. Fedak, M. Savard, Molecular mapping of novel genes controlling Fusarium head blight resistance and deoxynivalenol accumulation in spring wheat, Genome 46 (2003) 555564.

[50] M.S. Roder, V. Korzun, K. Wendehake, J. Plaschke, M. Tixier, A microsatellite map of wheat, Genetics 149 (1998) 2007-2023.

[51] E.D. Akhunov, A.W. Goodyear, S. Geng, L.L. Qi, B. Echalier, The organization and rate of evolution of wheat genomes are correlated with recombination rates along chromosome arms, Genome Res. 13 (2003) 753-763.

[52] M.L. Rota, M.E. Sorrells, Comparative DNA sequence analysis of mapped wheat ESTs reveals the complexity of genome rela- tionships between rice and wheat, Funct. Integr. Genom. 4 (2004) 34-46.

[53] S. Stack, L. Campbell, K. Henderson, I. Eujayl, M. Hannafey, W. Powell, P. Wolters, Development of EST-derived microsatellite markers for mapping and germplasm analysis in wheat, in: Proceedings \& Abstracts. Plant \& Animal Genome VIII. The International Conference on the Status of Plant \& Animal Genome Research, San Diego, USA, 9-12 January 2000, p. 227.

[54] H. Way, S. Chapman, L. McIntyre, R. Casu, G.P. Xue, J. Manners, R. Shorter, Identification of differentially expressed genes in wheat undergoing gradual water deficit stress using a subtractive hybridization approach, Plant Sci. 168 (2005) 661-670.

[55] R.Y. Zhang, Z.S. Xu, L.C. Li, M. Chen, Y. Z Ma, Isolation and expression analysis of a novel abiotic stress-induced gene W89 from wheat, Agric. Sci. China 6 (2007) 391-398.

[56] M.D. Adams, J.M. Kelley, J.D. Gocayne, M.H. Polymeropoulos, H. Xiao, C.R. Merril, A. Wu, B. Olde, R.F. Moreno, A.R. Kerlavage, W.R. McCombie, J.C. Venter, Complementary DNA sequencing: Expressed sequence tags and human genome project, Science 252 (1991) 1651-1656.

[57] T. Newman, F.J. de Bruijn, P. Green, K. Keegstra, H. Kende, L. McIntosh, J. Ohlrogge, N. Raikhel, S. Somerville, M. Thomashow, E. Retzel, C. Somerville, Genes galore: A summary of methods for accessing results from large-scale partial sequencing of anonymous Arabidopsis cDNA clones, Plant Physiol. 106 (1994) 1241-1255.

[58] S.D. Rounsley, A. Glodek, G. Sutton, M.D. Adams, C.R. Somerville, J.C. Venter, A.R. Kerlavage, The construction of Arabidopsis expressed sequence tag assemblies (a new resource to facilitate gene identification), Plant Physiol. 112 (1996) 11771183.

[59] N. Zouari, R.B. Saad, T. Legavre, J. Azaza, X. Sabau, M. Jaoua, K. Masmoudi, A. Hassairi, Identification and sequencing of ESTs from the halophyte grass Aeluropus littoralis, Gene 404 (2007) 61-69.

[60] M. Bevan, I. Bancroft, H.W. Mewes, R. Martienssen, R. McCombie, Clearing a path through the jungle: Progress in Arabidopsis genomics, Bioessays 21 (1999) 110-120.

[61] S.A. Goff, Rice as a model for cereal genomics, Curr. Opin. Plant Biol. 2 (1999) 86-89.

[62] J. Ning, B. Yuan, K.B. Xie, H.H. Hu, C.Q. Wu, L.Z. Xiong, Isolation and identification of SA and JA inducible protein kinase gene OsSJMK1 in rice, Acta Genet. Sin. 33 (2006) 625-633.

[63] V. Walbot, Genes, Genomes, Genomics. What can plant biologists expect from the 1998 National Science Foundation Plant Genome Research Program? Plant Physiol. 119 (1999) 11511155.

[64] T.E. Coramand, E.C.K. Pang, Isolation and analysis of candidate ascochyta blight defence genes in chickpea. Part I. Generation and analysis of an expressed sequence tag (EST) library, Physiol. Mol. Plant Pathol. 66 (2005) 192-200.

[65] Y.C. Wang, C.P. Yang, G.F. Liu, J. Jiang, Development of a cDNA microarray to identify gene expression of Puccinellia tenuiflora under saline-alkali stress, Plant Physiol. Biochem. 45 (2007) 567-576.

[66] R.K. Varshney, P. Langridge, A. Graner, Application of genomics to molecular breeding of wheat and barley, Adv. Genet. 58 (2007) 121-155.

[67] R. Schafleitner, R.O.G. Rosales, A. Gaudin, C.A.A. Aliaga, G.N. Martinez, L.R.T. Marca, L.A. Bolivar, F.M. Delgado, R. Simon, M. Bonierbale, Capturing candidate drought tolerance traits in 
two native Andean potato clones by transcription profiling of field grown plants under water stress, Plant Physiol. Biochem. 45 (2007) 673-690.

[68] N. Gutterson, J.Z. Zhang, Genomics applications to biotech traits: A revolution in progress? Curr. Opin. Plant Biol. 7 (2004) 226-230.

[69] J.M. Burke, J.C. Burger, M.A. Chapman, Crop evolution: From genetics to genomics, Curr. Opin. Genet. Dev. 17 (2007) 525532.

[70] B. Valliyodan, H.T. Nguyen, Understanding regulatory networks and engineering for enhanced drought tolerance in plants, Curr. Opin. Plant Biol. 9 (2006) 189-195.

[71] H. Campos, M. Cooper, J.E. Habben, G.O. Edmeades, J.R. Schussler, Improving drought tolerance in maize: a view from industry, Field Crops Res. 90 (2004) 19-34.

[72] A. Kathiresan, H.R. Lafitte, J.X. Chen, L. Mansueto, R. Bruskiewich, J. Bennett, Gene expression microarrays and their application in drought stress research, Field Crops Res. 97 (2006) 101-110.

[73] M. Morgante, F. Salamini, From plant genomics to breeding practice, Curr. Opin. Biotechnol. 14 (2003) 214-219.

[74] B. Lemieux, A. Aharoni, M. Schena, Overview of DNA chip technology, Mol. Breed 4 (1998) 277-289.

[75] P. Hieter, M. Boguski, Functional Genomics: It's all how you read it, Science 278 (1997) 601-604.

[76] G.H. Salekdeh, J. Siopongco, L.J. Wade, B. Ghareyazie, J. Bennett, A proteomic approach to analyzing drought- and saltresponsiveness in rice, Field Crops Res. 76 (2002) 199-219.

[77] M. Schena, D. Shalon, R.W. Davis, P.O. Brown, Quantitative monitoring of gene expression patterns with a complementary DNA microarray, Science 270 (1995) 467-470.
[78] Y. Ruan, J. Gilmore, T. Conner, Towards Arabidopsis genome analysis: monitoring expression profiles of 1400 genes using cDNA microarrays, Plant J. 15 (1998) 821-833.

[79] D.M. Kehoe, P. Villand, S. Sommerville, Microarrays for studies of higher plants and other photosynthetic organisms, Trends Plant Sci. 4 (1999) 38-41.

[80] H. Leung, Stressed genomics - bringing relief to rice fields, Curr. Opin. Plant Biol. 11 (2008) 201-208.

[81] N. Sreenivasulu, S.K. Sopory, P.B.K. Kishor, Deciphering the regulatory mechanisms of abiotic stress tolerance in plants by genomic approaches, Gene 388 (2007) 1-13.

[82] T. Abebe, A.C. Guenzi, B. Martin, J.C. Chushman, Tolerance of mannitol-accumulating transgenic wheat to water stress and salinity, Plant Physiol. 131 (2003) 1748-1755.

[83] A. Pellegrineschi, M. Reynolds, M. Pacheco, R.M. Brito, R. Almeraya, K. Yamaguchi-Shinozaki, D. Hoisington, Stressinduced expression in wheat of the Arabidopsis thaliana DREB1A gene delays water stress symptoms under greenhouse conditions, Genome 47 (2004) 493-500

[84] E. Sivamani, A. Bahieldin, J.M. Wraith, T. Al-Niemi, W.E. Dyer, T.H.D. Ho, R. Qu, Improved biomass productivity and water use efficiency under water deficit conditions in transgenic wheat constitutively expressing the barley HVAl gene, Plant Sci. 155 (2000) 1-9.

[85] C.S. Jang, H.J. Lee, S.J. Chang, Y.W. Seo, Expression and promoter analysis of the TaLTP1 gene induced by drought and salt stress in wheat (Triticum aestivum L.), Plant Sci. 167 (2004) 995-1001.

[86] G. Singh, M. Jain, R. Kulshreshtha, J.P. Khurana, S. Kumar, P. Singh, Expression analysis of genes encoding translation initiation factor 3 subunit $g$ (TaeIF3g) and vesicle-associated membrane protein-associated protein (TaVAP) in drought tolerant and susceptible cultivars of wheat, Plant Sci. 173 (2007) 660-669. 